AperTO - Archivio Istituzionale Open Access dell'Università di Torino

\title{
Lupus nephritis and pregnancy outcome
}

\section{This is the author's manuscript}

Original Citation:

Availability:

This version is available http://hdl.handle.net/2318/1704739

since 2019-06-20T09:42:56Z

Published version:

DOI:10.1016/j.autrev.2017.02.001

Terms of use:

Open Access

Anyone can freely access the full text of works made available as "Open Access". Works made available under a Creative Commons license can be used according to the terms and conditions of said license. Use of all other works requires consent of the right holder (author or publisher) if not exempted from copyright protection by the applicable law. 


\section{Accepted Manuscript}

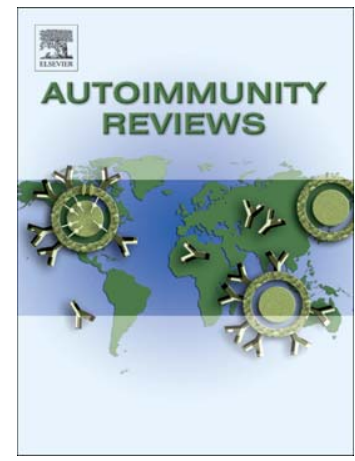

Lupus nephritis and pregnancy outcome

Karen Schreiber, Ksenija Stach, Savino Sciascia

PII: $\quad$ S1568-9972(17)30029-0

DOI: $\quad$ doi: $10.1016 / j . a u t r e v .2017 .02 .001$

Reference: $\quad$ AUTREV 1967

To appear in: $\quad$ Autoimmunity Reviews

Received date: 23 January 2017

Accepted date: $\quad 27$ January 2017

Please cite this article as: Schreiber Karen, Stach Ksenija, Sciascia Savino, Lupus nephritis and pregnancy outcome, Autoimmunity Reviews (2017), doi:10.1016/j.autrev.2017.02.001

This is a PDF file of an unedited manuscript that has been accepted for publication. As a service to our customers we are providing this early version of the manuscript. The manuscript will undergo copyediting, typesetting, and review of the resulting proof before it is published in its final form. Please note that during the production process errors may be discovered which could affect the content, and all legal disclaimers that apply to the journal pertain. 
Karen Schreiber, Centre for Thrombosis, Guy's and St Thomas' NHS Foundation Trust, London, UK; Department of Rheumatology, Copenhagen University Hospital, Copenhagen, Denmark

Address for correspondence: Karen.schreiber@gstt.nhs.uk

Ksenija Stach, $1^{\text {st }}$ Medical Department, University Medical Centre Mannheim, Medical Faculty Mannheim, University of Heidelberg, Germany

Savino Sciascia, Department of Clinical and Biological Sciences, Center of Research of Immunopathology and Rare Diseases- Coordinating Center of the Network for Rare Diseases of Piedmont and Aosta Valley, San Giovanni Hospital, University of Turin, piazza del donatore di Sangue 3, 10054 Turin, Italy. 
Dear editor,

Pregnancy success rates in women with systemic lupus erythematosus (SLE) have improved significantly in recent years, in that pregnancy morbidity has been reduced from $40 \%$ in the early 1960 's to less than $15 \%$ in recent years [1]. Pregnancy was previously discouraged in women with SLE, but the twenty-first century has brought focus on pregnancy management and in maternal and fetal outcomes and recent data suggest that women with stable SLE (if adequately treated) have favourable pregnancy outcomes with live birth rates as high as $80 \%$ [2]. In a systematic review on observational studies, Smyth et al found that in patients with SLE, both lupus nephritis (LN) and antiphospholipid antibodies (aPL) increase the risks for maternal hypertension and premature births[3].

We would like to congratulate Moroni and her team for publishing the first prospective multicentre data on maternal and fetal pregnancy outcomes in women with a history of LN [4, 5]. These data are urgently needed and provide a further piece in the puzzle towards a more complete picture in the understanding of pregnancy outcomes in women with SLE and in particular in patients with underlying LN. The only previous prospective data on women with LN focused on SLE activity after switching mycofenolate mofetil maintenance to azathioprine prior to conception [6].

Moroni et al included 61 women (59 Caucasians and 2 Asians) assessing 71 pregnancies followed from 2006-2013, who fulfilled the American College of Rheumatology (ACR) classification criteria for SLE, with a biopsy or clinically diagnosed LN and who fell pregnant in the above mentioned period attending the pregnancy clinic 3 months prior to conception. Women were closely followed up on a monthly basis.

Assessing maternal outcomes, $19.7 \%$ of the patients flared $(18.3 \%$ were reported as mild and 1.7\% as severe), $8.4 \%$ developed pre-eclampsia and two cases developed haemolysis and 
elevated liver enzymes and low platelet count (HELLP syndrome). Predictors of maternal outcomes were SLE duration, previous renal flares and arterial hypertension, whereas significant predictors of flares were BMI, hypo-complementaemia (low C3 and C4), antidouble-stranded DNA antibodies and anti-C1q antibodies [4].

With regards to fetal outcomes, the reported live birth rate was $91.8 \%$, and the $8.2 \%$ fetal loss rate was divided into $4.1 \%$ miscarriages (in this study defined as pregnancy loss $<20$ weeks of gestation) and $4.1 \%$ stillbirths. Of the live-births, $61 \%$ were delivered at term, $30 \%$ were born pre-term and $27 \%$ had a birth weight $<2500 \mathrm{~g}$. All patients received aspirin. Factors associated with fetal loss were lupus anticoagulant, anti-cardiolpipin IgG, anti- $\beta$ glycoprotein-I and pre-existing arterial hypertension. SLE activity, proteinuria, a history of renal flares, arterial hypertension and active LN increases the risk of preterm delivery [5].

There are three aspects of particular note with regards to fetal outcomes which supplement previous data very nicely; Firstly, that an increase in SLEDAI and proteinuria seem to increase the likelihood for preterm delivery. Albeit based on a relatively low event rate, this information was not available from previous data and might guide clinicians in their decision making in the management of these patients. Secondly, a reassuringly low rate of fetal loss was observed (in this study defined as neonatal death within 28 days post delivery). It may well be that this has been influenced by the fact that all women were treated with aspirin. Thirdly, an interesting observation was that women who were taking hydroxychloroquine (HCQ) had a significantly reduced risk to deliver a small for gestational aged baby $(\mathrm{p}=0.023)$. In their cohort Moroni et al reported that 54.4\% of women were treated with HCQ. It would be most interesting to know if these women treated with HCQ had more favourable classes of LN, if they generally had more stable disease profiles, if HCQ was given as adjuvant therapy in addition to other immunosuppressive or anticoagulation therapy and most importantly if 
these women were more likely to have persistent aPL?

HCQ is currently experiencing its 'renaissance' in the field of antiphospholipid syndrome (APS) [7] and has recently been shown to improve pregnancy outcomes in women with aPL and APS $[8,9]$. Its favourable safety profile especially in regards to pregnancy and lactation makes it an interesting agent for the use in pregnancy. Latest the British Society for Rheumatology (BSR) has recommended HCQ as 'the antimalarial of choice in women requiring immune modulation in pregnancy' $[10,11]$. It would be interesting to know if HCQ in the future also will have a more substantial post in the armamentarium available for LN and prospective studies defining HCQ’s role in autoimmune diseases are therefore urgently needed[7, 12].

It is worth remembering that patients included in this study were mainly Caucasian, and it may therefore be difficult to draw conclusions for all pregnant LN patients. Moreover, the team report that $21.1 \%$ of the patients had pre pregnancy LN activity (full remission was only present in 78.9\%), which seems rather high given the fact that in general full disease remission is recommended for at least 6 months prior to conception [13]. Thus, pregnancy outcomes may have been even more encouraging if these cases were excluded from analysis. However, at the end of the day every clinician has experienced that real patients are not always compliant with textbook recommendations, and these data therefore provide valuable information how to gauge patients in full remission and those with mild LN activity prior to embarking pregnancy. Once more this study highlights the importance of specialist multidisciplinary teams and pregnancy counselling in women with pre-existing medical illnesses [14][15]. 


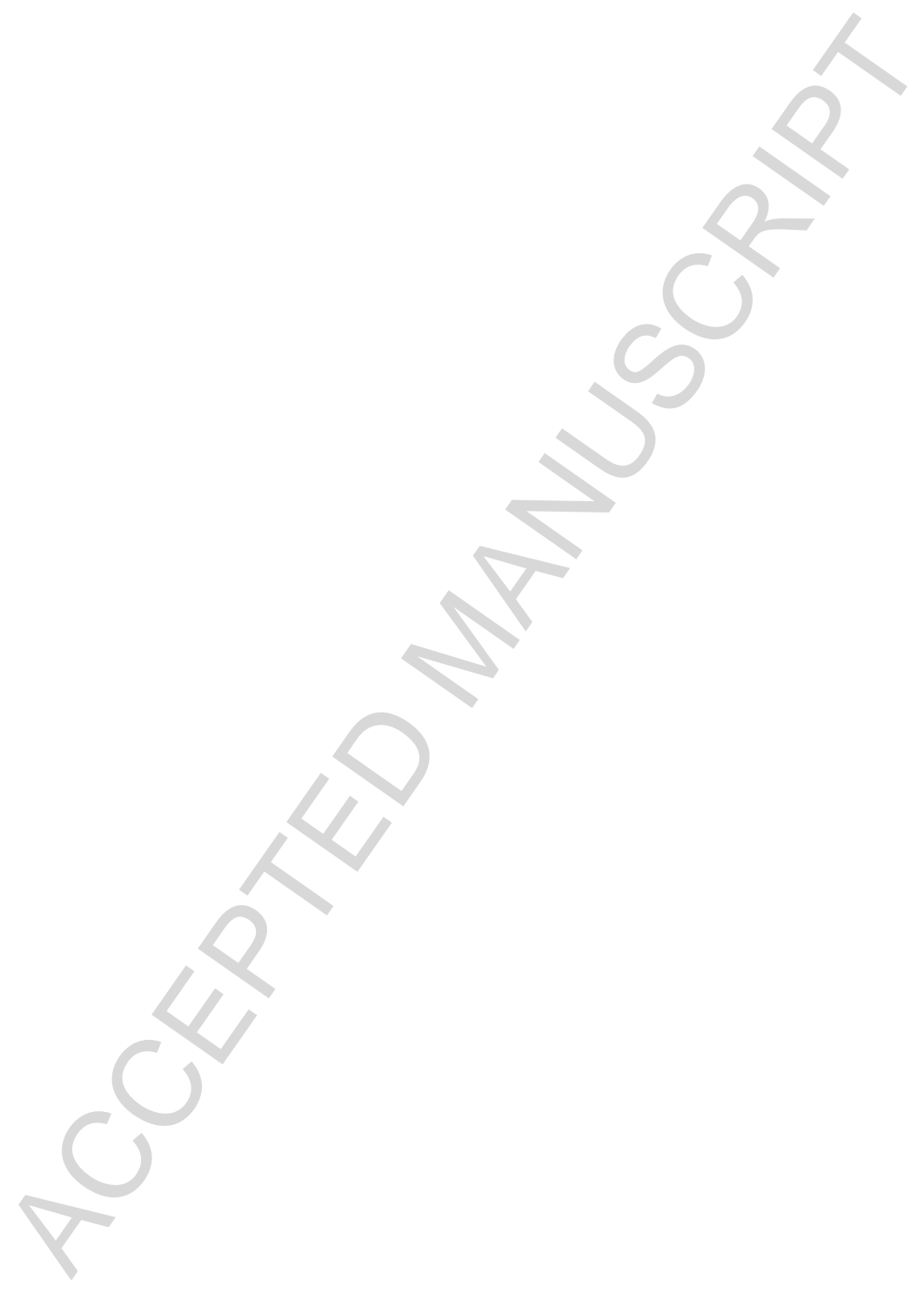


1. Clark, C.A., K.A. Spitzer, and C.A. Laskin, Decrease in pregnancy loss rates in patients with systemic lupus erythematosus over a 40-year period. J Rheumatol, 2005. 32(9): p. 1709-12.

2. Buyon, J.P., et al., Predictors of Pregnancy Outcomes in Patients With Lupus: A Cohort Study. Ann Intern Med, 2015.

3. Smyth, A., et al., A systematic review and meta-analysis of pregnancy outcomes in patients with systemic lupus erythematosus and lupus nephritis. Clin J Am Soc Nephrol, 2010. 5(11): p. 2060-8.

4. Moroni, G., et al., Maternal outcome in pregnant women with lupus nephritis. A prospective multicenter study. J Autoimmun, 2016. 74: p. 194-200.

5. Moroni, G., et al., Fetal outcome and recommendations of pregnancies in lupus nephritis in the 21st century. A prospective multicenter study. J Autoimmun, 2016. 74: p. 6-12.

6. Fischer-Betz, R., et al., Low risk of renal flares and negative outcomes in women with lupus nephritis conceiving after switching from mycophenolate mofetil to azathioprine. Rheumatology (Oxford), 2013. 52(6): p. 1070-6.

7. Erkan, D., et al., 14th International Congress on Antiphospholipid Antibodies: task force report on antiphospholipid syndrome treatment trends. Autoimmun Rev, 2014. 13(6): p. 685-96.

8. Sciascia S, H.B., Talavera-Garcia E, Lliso G, Khamashta MA and Cuadrado MJ, The impact of hydroxychloroquine treatment on pregnancy outcome in women with antiphospholipid antibodies. accepted in American Journal of Obstetrics \& Gynecology, 2015.

9. Mekinian, A., et al., The efficacy of hydroxychloroquine for obstetrical outcome in antiphospholipid syndrome: Data from a European multicenter retrospective study. Autoimmun Rev, 2015. 14(6): p. 498-502. 
10. Flint, J., et al., BSR and BHPR guideline on prescribing drugs in pregnancy and breastfeeding-Part II: analgesics and other drugs used in rheumatology practice. Rheumatology (Oxford), 2016.

11. Flint, J., et al., BSR and BHPR guideline on prescribing drugs in pregnancy and breastfeeding-Part I: standard and biologic disease modifying anti-rheumatic drugs and corticosteroids. Rheumatology (Oxford), 2016.

12. Schreiber K., S.S., Breen K., Jacobsen S., Farquharson R., Middeldorp S., Regan L., Hunt BJ, HYPATIA - A prospective randomised controlled trial of HYdroxychoroquine versus placebo during Pregnancy in women with AnTIphospholipid Antibodies. ISTH, 2015.

13. Kwok, L.W., et al., Predictors of maternal and fetal outcomes in pregnancies of patients with systemic lupus erythematosus. Lupus, 2011. 20(8): p. 829-36.

14. Ruiz-Irastorza, G. and M.A. Khamashta, Lupus and pregnancy: ten questions and some answers. Lupus, 2008. 17(5): p. 416-20.

15. Cantwell, R., et al., Saving Mothers' Lives: Reviewing maternal deaths to make motherhood safer: 2006-2008. The Eighth Report of the Confidential Enquiries into Maternal Deaths in the United Kingdom. BJOG, 2011. 118 Suppl 1: p. 1-203. 